\title{
AVALIAÇÃO MICROBIOLÓGICA DAS AREIAS E DA ÁGUA DAS PRAIAS DOS MUNICÍPIOS LITORÂNEOS QUE FORMAM A COSTA DAS BALEIAS
}

\author{
Luma Ferreira França1, Júlia Apolinária Casagrande ${ }^{2}$ e Jorge Luiz Fortuna
}

\begin{abstract}
Resumo: $A$ água é um dos principais meios de veiculação de doenças infecciosas e parasitárias, porém a areia da praia também é uma importante fonte de transmissão destas doenças aos frequentadores das praias. Devido ao uso constante desses ambientes, principalmente por serem cidades turísticas, o monitoramento microbiológico se faz necessário, podendo vir a reduzir possíveis riscos à saúde dos frequentadores. Este estudo teve como objetivo avaliar a qualidade de balneabilidade das areias e da água das praias dos municípios litorâneos que formam a Costa das Baleias, no Extremo Sul do estado da Bahia. As análises microbiológicas das areias e da água realizadas foram: enumeração de coliformes termotolerantes; pesquisa de Escherichia coli; contagem de Enterococcus spp. e contagem de fungos filamentosos e leveduras. As águas e areias analisadas apresentaram níveis de contaminação relevantes em relação à higiene-sanitária das praias, observando uma maior contaminação das areias em relação a água e maior detecção de Enterococcus spp. em relação aos coliformes termotolerantes.
\end{abstract}

Palavras-chave: Água do mar. Praia. Coliformes. Enterococcus. Balneabilidade.

\section{Introdução}

Conhecendo a importância das relações entre o homem e a natureza, a praia se torna um vínculo dessa relação. Seja inicialmente para lazer, como também para turismo que se apresenta como fonte de renda para a comunidade nativa $e$ exploração de seus recursos naturais e também promoção de saúde, sendo um incentivador do esporte. Contudo, as praias sofrem alterações em função do mau uso da população sem consciência ambiental. Essas alterações podem vir a se tornar irreversíveis, se a população não agir de forma responsável.

A poluição das praias também ocorre devido ao encontro da água do mar com a praia já poluída que vem a ser intensificada pela ação dos banhistas, tendo em vista que essas praias não apresentam coleta adequada de resíduo sólido e líquido, entre outros. A água e a areia da praia passam a ter função de meio para o cultivo de microrganismos e disseminação de doenças causadas pelos mesmos.

Devido a constante presença humana nesses ambientes e tendo em vista a fragilidade quanto à preservação, o monitoramento biológico se faz necessário, podendo vir a reduzir os impactos envolvidos com a saúde dos banhistas expostos, além de ser uma forma de subsidiar ações que reduzem os riscos à saúde pública $e$ promovem a preservação e recuperação do litoral.

Milhares de pessoas adquirem
doenças (conjuntivites, infecções em ouvidos, problemas dermatológicos $e$ gastrointestinais) durante um simples banho de mar ou mesmo ao se deitar em areias de praias contaminadas (ARAÚJO et al., 2014).

Entre os principais microrganismos patogênicos destacam-se espécies de bactérias encontradas tanto no trato gastrintestinal de humanos e de outros animais de sangue quente (Escherichia coli), como também as não entéricas (Citrobacter spp., Klebsiella spp. e Serratia spp.) (SILVA et al. 2007).

Segundo Castro (2003), dentre os indicadores microbiológicos de poluição fecal, o grupo coliforme é o mais empregado sendo a Escherichia coli a de maior significado clínico para o homem devido ao seu papel como patógeno oportunista, causando infecções no sangue, feridas e trato urinário.

\footnotetext{
1E-mail: lumanuck@gmail.com

²E-mail: julia_casagrande2010@hotmail.com 


\section{REA - Revista de estudos ambientais (Online) v.20, n. 1, p.44-57, jan./jun. 2018}

O gênero Enterococcus também é usado como indicador de contaminação e apresenta espécies associadas com animais e plantas, mas apenas as espécies isoladas em humanos e outros animais é que apresentam importância sanitária (HOLT et al., 1994).

Os fungos estão bem difundidos na natureza, vivendo no solo, no ar e na água. $A$ maioria é mesófila (SILVA et al., 2007), sendo que alguns podem causar doenças como infecções cutâneas, das mucosas, principalmente em mulheres, nas unhas e mais raramente, infecções disseminadas e profundas em indivíduos debilitados ou imunodeprimidos (MONTEIRO, 2013). As leveduras causadoras de doenças humanas mais importantes são as espécies: Candida albicans que pode ser encontrada em fezes humanas e Cryptococcus neoformans em excrementos de pombos e outras aves.

Este trabalho teve como objetivo avaliar a qualidade de balneabilidade das areias e da água do mar das praias dos municípios litorâneos que formam a Costa das Baleias, no Extremo Sul do estado da Bahia.

\section{Metodologia}

\section{1 Área de estudo e coleta das amostras}

O extremo Sul baiano é formado por vinte e um municípios, sendo que seus limites geográficos são formados ao Norte, pelas regiões Sudoeste e Litoral Sul da Bahia; ao Sul, pelo estado do Espírito Santo; a Oeste, pelo estado de Minas Gerais; e a Leste, pelo Oceano Atlântico. Apresenta como principal via de acesso a BR-101, uma das principais rodovias brasileiras que liga três importantes regiões brasileiras (Sul, Sudeste e Nordeste).

Situada no extremo Sul da Bahia a Costa das Baleias compreende os municípios de Alcobaça, Prado, Caravelas, Nova Viçosa e Mucuri. A Costa das Baleias se apresenta como um importante atrativo de ecoturismo, abrangendo as praias tropicais, corais e manguezais que compõem a costa, além de ser berçário de baleias como a Jubarte (Megaptera novaeangliae) que encontram em suas águas temperatura ideal para sua reprodução.

As coletas das amostras das areias e da água do mar foram realizadas nas duas principais praias dos respectivos municípios da Costa das Baleias: Prado, Alcobaça, Caravelas, Nova Viçosa e Mucuri, totalizando dez praias. Realizaram-se quatro coletas de amostras das areias (areia seca e areia molhada) e da água do mar em cada praia, totalizando 40 amostras, respectivamente. As coletas foram realizadas em maio, agosto e novembro de 2015 e abril de 2016.

$\mathrm{Na}$ zona de areia seca, onde normalmente há maior concentração de banhistas, foi traçado uma linha imaginária à costa e retirou-se três subamostras (A-B-C) em três diferentes pontos equidistantes de 15 metros.

Depois de homogeneizada, no Laboratório de Microbiologia, estas três subamostras constituíram uma amostra composta representativa da área em estudo. $\mathrm{Na}$ zona de areia molhada (D-E-F), principal área em que as crianças frequentam mais intensamente, foi utilizada a mesma metodologia de coleta de amostra que na zona de areia seca (Figura 1).

Figura 1 - Visualização dos pontos de coletas das areias e da água do mar

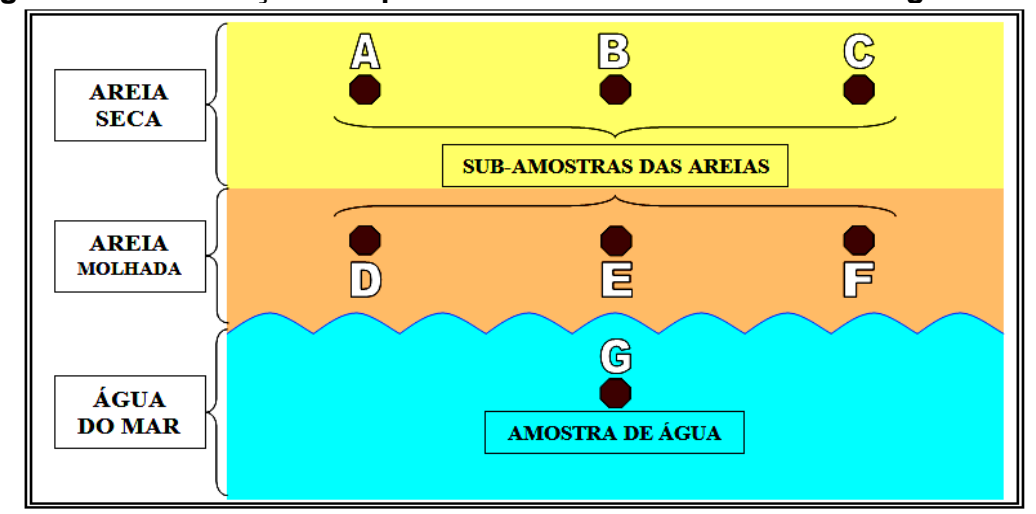

Fonte: Autores (2018)

A coleta das areias foi realizada em cada ponto a uma profundidade de 15 centímetros utilizando-se sacos plásticos $(15 \times 30 \mathrm{~cm})$ que foram identificados $e$ 


\section{REA - Revista de estudos ambientais (Online) v.20, n. 1, p.44-57, jan./jun. 2018}

transportados até o Laboratório de Microbiologia do Campus X da Universidade do Estado da Bahia (UNEB), em recipientes isotérmicos contendo gelo.

A coleta da água ( $G$ ) foi efetuada em cada praia, onde também ocorreram as coletas das areias, na sua zona central utilizando um frasco de vidro esterilizado de $300 \mathrm{~mL}$ com tampa. Coletou-se a água cerca de $30 \mathrm{~cm}$ da superfície em um ponto com aproximadamente $80 \mathrm{~cm}$ de profundidade. Os frascos foram identificados e transportados para o Laboratório de Microbiologia do Campus $\mathrm{X}$ da Universidade do Estado da Bahia (UNEB), em recipientes isotérmicos contendo gelo.

\subsection{Análises microbiológicas}

As análises microbiológicas de enumeração de coliformes termotolerantes; pesquisa de Escherichia coli; contagem de Enterococcus spp. e contagem de fungos filamentosos e leveduras foram realizadas baseadas nos métodos padronizados para exame de água e esgoto (Standard Methods for the Examination of Water and Wastewater) da Associação Americana de Saúde Pública (American Public Health Association) (APHA, 2005).

\subsubsection{Amostras das areias}

As três subamostras das areias, da mesma zona de coleta (seca ou molhada), foram colocadas em um único Erlenmeyer esterilizado e após a homogeneização desta amostra conjunta, foram transferidos $30 \mathrm{~g} \mathrm{da}$ areia para outro Erlenmeyer e adicionado $270 \mathrm{~mL}$ de Solução Salina Peptonada (SSP) a $0,1 \%$ de modo a obter uma diluição de $10^{-}$ 1. Após nova homogeneização, esta diluição ficou em repouso durante 30 minutos. Em seguida, se retirou 1,0 mL desta diluição $10^{-1}$ transferindo-a para um tubo de ensaio contendo 9,0 mL de SSP, obtendo assim a diluição de $10^{-2}$. Repetiu-se o mesmo método com a diluição de $10^{-2}$, obtendo-se assim a diluição de $10^{-3}$.

\subsubsection{Amostra de água do mar}

Após a homogeneização da amostra, no próprio frasco da coleta, transferiu-se, com o auxílio de micropipeta, $1,0 \mathrm{~mL}$ da amostra para tubo de ensaio contendo 9,0
$\mathrm{mL}$ de Solução Salina Peptonada (SSP) a $0,1 \%$ de modo a obter uma diluição de $10^{-1}$. Em seguida, se retirou 1,0 mL desta diluição $10^{-1}$ transferindo-a para um tubo de ensaio contendo 9,0 mL de SSP, obtendo assim a diluição de $10^{-2}$. Repetiu-se o mesmo método com a diluição de $10^{-2}$, obtendo-se assim a diluição de $10^{-3}$.

\subsection{Enumeração de coliformes termotolerantes}

Foram três séries de três tubos, com tubo de Durhan, contendo Caldo Lauril Sulfato Triptose (LST), onde foram adicionados $1,0 \mathrm{~mL}$ de cada diluição, e incubados à $35^{\circ} \mathrm{C} / 24-48 \mathrm{~h}$. Aqueles que apresentaram formação de gás no interior do tubo de Durhan e tornaram o meio turvo foram considerados positivos, portanto seguiram para a próxima etapa.

De cada tubo positivo de LST uma alíquota foi transferida por meio de alça bacteriológica, para tubos contendo caldo para Escherichia coli (EC), que foram incubados em banho-maria com circulação de água à 45ํㅡ/24-48 h, para contagem de coliformes termotolerantes. Os tubos positivos do caldo EC foram conferidos nas tabelas de Número Mais Provável (NMP) para a enumeração de coliformes termotolerantes.

\subsection{Enumeração de Enterococcus spp.}

Três séries de três tubos contendo Caldo Glicose Azida (CGA) foram empregados, nos quais foram adicionados $1,0 \mathrm{~mL}$ de cada diluição, e incubados à $35^{\circ} \mathrm{C} / 24-48$ h. Aqueles que apresentaram turvação no meio foram considerados positivos.

\subsection{Contagem de fungos filamentosos e leveduras}

A partir das diluições $\left(10^{-1} ; 10^{-2} ; 10^{-3}\right)$ de SSP transferiu-se alíquotas de $0,1 \mathrm{~mL}$ para respectivas placas de Petri contendo Ágar Sabouraud Dextrose (ASD) com ácido tartárico. A semeadura foi feita por espalhamento utilizando-se alças de Drigaslky - método de espalhamento em superfície (spread plate). As placas foram incubadas, em posição normal, a 


\section{REA - Revista de estudos ambientais (Online) v.20, n. 1, p.44-57, jan./jun. 2018}

temperatura ambiente e/ou em estufa a $25^{\circ} \mathrm{C} / 3-5$ dias.

\subsection{Análise estatística}

Utilizou-se a análise de variância (teste de Tukey) (AYRES et al., 2007) para verificar se houve diferença significativa $(p<0,001)$ entre os valores encontrados de contaminação pelos respectivos microrganismos pesquisados e entre o nível de contaminação da água e das areias analisadas.

\section{Resultados e discussão}

As águas salinas destinadas à balneabilidade (recreação de contato primário) têm sua condição avaliada nas categorias de classificação em Própria e Imprópria. A água do mar é considerada Imprópria para o banho, de acordo com Resolução CONAMA ㄲo 274 (BRASIL, 2000), quando apresenta os seguintes índices: coliformes termotolerantes $>1,0 \times 10^{3}$ $\mathrm{NMP} / 100 \mathrm{~mL}(>3,0$ log NMP/100 mL); Enterococcus spp. $>1,0 \times 10^{2} \mathrm{NMP} / 100 \mathrm{~mL}$ $(>2,0 \log \mathrm{NMP} / 100 \mathrm{~mL})$. Para fungos não há padrão. Sendo que quando considerada Própria a água do mar pode ser subdividida nas seguintes categorias: Excelente; Muito Boa e Satisfatória de acordo com o nível tolerável de contaminação por 100 mililitros (BRASIL, 2000).

Como não existem padrões disponíveis ou valores limites estabelecidos para areia pela legislação brasileira, esta pesquisa utilizou valores estabelecidos por Mendes, Nascimento e Oliveira (1993); Vaz et al. (2005); Valdez e Grosbelli (2012) para coliformes termotolerantes (>1,0 $\times 10^{5}$ $\mathrm{NMP} / 100 \mathrm{~g}$ ou $>5,0 \log \mathrm{NMP} / 100 \mathrm{~g}$ ) e fungos $\left(>1,0 \times 10^{5}\right.$ UFC/100 g ou $>5,0$ log NMP/100 g); e pela Associação Bandeira Azul da Europa (ABAE, 2002) para os Enterococcus spp. $\left(>2,0 \times 10^{3} \mathrm{NMP} / 100 \mathrm{~g}\right.$ ou $>3,3 \log$ NMP/100 g).

Em relação à enumeração de coliformes termotolerantes na água das praias analisadas, todas encontravam-se próprias, sendo $33(82,5 \%)$ classificadas como excelente; quatro $(10 \%)$ em muito Boa e três $(7,5 \%)$ satisfatória. Porém, a contagem de enterococos indicou que 14 (35\%) amostras de água das praias encontravamse impróprias em relação à balneabilidade, não sendo recomendado seu contato primário de acordo com a resolução CONAMA no 274 (BRASIL, 2000). Das 26 (65\%) amostras de água próprias, em relação aos enterococos, todas foram classificadas como excelente (Tabelas 1 a 4).

Segundo o descrito na resolução CONAMA no 274 (BRASIL, 2000), quando se utiliza mais de um indicador microbiológico, as águas terão as suas condições avaliadas de acordo com o critério mais restritivo, neste caso, Enterococcus spp. Além disso, ainda de acordo com esta resolução, os padrões referentes aos enterococos aplicam-se somente às águas marinhas. Não existem padrões para contaminação de fungos em água do mar.

Barros, Marques e Morais (2015), ao analisarem a balneabilidade da água das praias da capital do estado do Tocantins, Palmas, por meio da técnica substrato Cromogênico Colilert chegaram ao resultado de que todas as praias eram classificadas como "próprias" para banho, nos cinco períodos amostrais avaliados. As menores contagens de $E$. coli $(1,0$ a $7,4 \mathrm{NMP} / 100 \mathrm{~mL})$ ocorreram no período de "seca" da região, enquanto que as maiores contagens de $E$. coli (35,5 a 1.553,1 NMP/100 mL) ocorreram no período chuvoso. Para o autor, este padrão indica que o início das chuvas é responsável pelo carreamento de contaminações difusas nas praias.

Valadão e Araújo (2012), analisando a qualidade da água das praias de Natal-RN durante o período de 2004 a 2009, constataram em várias semanas que os limites encontrados, em algumas praias, eram de centenas de milhares de coliformes termotolerantes, cujo pico ocorreu na semana 170 (correspondendo à semana $14 / 2005$, mês de abril) no valor de 900.000 NMP/100 mL. Segundo os autores estes altos valores de coliformes termotolerantes encontrados em um dos locais de amostragem, mostrou que a situação de contaminação em que se encontra a praia Via Costeira/Mãe Luiza exige que medidas mitigadoras e ações que visem a redução e/ou eliminação dos agentes causadores das contaminações sejam tomadas pela prefeitura e órgãos de fiscalização ambiental. As amostras foram coletadas em sete estações localizadas em Natal, ao longo de 52 semanas e classificadas de acordo com a resolução CONAMA no 274 (BRASIL, 2000) com base no Número Mais Provável (NMP). Também foram realizadas análises de evolução da qualidade ambiental com base 


\section{REA - Revista de estudos ambientais (Online)}

v.20, n. 1, p.44-57, jan./jun. 2018

nos percentuais anuais apresentados para cada uma das estações de monitoramento. Tal análise permite avaliar se houve uma melhoria ou não na sua qualidade, possibilitando a adoção de medidas preventivas em caso de perda de qualidade. Os resultados indicaram que, de forma geral, as praias de Natal possuem boa qualidade ambiental.

\begin{tabular}{|c|c|c|c|c|}
\hline $\begin{array}{l}\text { PRAIAS } \\
\text { (CIDADES) }\end{array}$ & AMOSTRAS & $\begin{array}{c}\text { COLIFORMES } \\
\text { TERMOTOLERANTES } \\
\log \text { NMP } / 100 \mathrm{~mL}(\mathrm{~g})\end{array}$ & $\begin{array}{c}\text { Enterococcus } \\
\text { spp. } \\
\text { log NMP/100 } \\
\mathrm{mL}(\mathrm{g})\end{array}$ & $\begin{array}{c}\text { FUNGOS } \\
\log \text { UFC/100 } \\
\mathrm{mL}(\mathrm{g})\end{array}$ \\
\hline \multirow{3}{*}{$\begin{array}{c}\text { Grauçá } \\
\text { (Caravelas-BA) }\end{array}$} & $1 A G$ & 0,0000 & 3,5798 & 2,6990 \\
\hline & $1 \mathrm{AS}$ & 2,9638 & 3,0414 & 3,7404 \\
\hline & $1 \mathrm{AM}$ & 3,3222 & 0,0000 & 3,6812 \\
\hline \multirow{3}{*}{$\begin{array}{c}\text { Barra } \\
\text { (Caravelas-BA) }\end{array}$} & $2 A G$ & 2,5563 & 3,3617 & 3,4150 \\
\hline & $2 A S$ & 3,9685 & 1,6335 & 3,2788 \\
\hline & $2 \mathrm{AM}$ & 4,0792 & 0,4771 & 4,3802 \\
\hline \multirow{3}{*}{$\begin{array}{c}\text { Centro } \\
\text { (Prado-BA) }\end{array}$} & $3 A G$ & 2,5563 & 3,3617 & 2,0000 \\
\hline & $3 \mathrm{AS}$ & 5,0414 & 2,3802 & 4,2041 \\
\hline & $3 \mathrm{AM}$ & 6,3222 & 1,5798 & 4,0792 \\
\hline \multirow{3}{*}{$\begin{array}{l}\text { Coqueiral } \\
\text { (Prado-BA) }\end{array}$} & $4 A G$ & 2,9638 & 3,1761 & 2,8451 \\
\hline & $4 \mathrm{AS}$ & 5,0414 & 1,8751 & 4,3424 \\
\hline & $4 \mathrm{AM}$ & 2,5563 & 1,3010 & 3,8062 \\
\hline \multirow{3}{*}{$\begin{array}{c}\text { Corais } \\
(\text { Alcobaça-BA })\end{array}$} & $5 A G$ & 0,0000 & 3,6335 & 2,8451 \\
\hline & 5 AS & 2,4771 & 1,6335 & 4,5798 \\
\hline & $5 \mathrm{AM}$ & 3,3617 & 1,6335 & 7,5798 \\
\hline \multirow{3}{*}{$\begin{array}{c}\text { Centro } \\
(\text { Alcobaça-BA })\end{array}$} & $6 A G$ & 0,0000 & 3,6335 & 0,0000 \\
\hline & $6 \mathrm{AS}$ & 2,5563 & 3,0414 & 3,7993 \\
\hline & $6 \mathrm{AM}$ & 2,5563 & 2,3222 & 3,4914 \\
\hline \multirow{3}{*}{$\begin{array}{c}\text { Centro } \\
\text { (Mucuri-BA) }\end{array}$} & $7 \mathrm{AG}$ & 0,0000 & 2,5563 & 5,3424 \\
\hline & 7 AS & 2,5563 & 2,6628 & 4,2304 \\
\hline & $7 \mathrm{AM}$ & 2,5563 & 1,8751 & 2,7782 \\
\hline \multirow{3}{*}{$\begin{array}{l}\text { Baia do Sol } \\
\text { (Mucuri-BA) }\end{array}$} & $8 \mathrm{AG}$ & 0,0000 & 2,9638 & 2,0000 \\
\hline & $8 \mathrm{AS}$ & 0,0000 & 1,3617 & 0,0000 \\
\hline & $8 \mathrm{AM}$ & 2,0000 & 1,9685 & 3,2304 \\
\hline \multirow{3}{*}{$\begin{array}{l}\text { Lugar Comum } \\
\text { (Nova Viçosa- } \\
\text { BA) }\end{array}$} & $9 A G$ & 0,0000 & 3,0362 & 0,0000 \\
\hline & 9 AS & 3,7243 & 4,3802 & 3,0000 \\
\hline & $9 \mathrm{AM}$ & 3,1761 & 1,9685 & 3,9912 \\
\hline \multirow{3}{*}{$\begin{array}{l}\text { Pau Fincado } \\
\text { (Nova Viçosa- } \\
\text { BA) }\end{array}$} & $10 \mathrm{AG}$ & 0,0000 & 3,5798 & 3,2788 \\
\hline & $10 \mathrm{AS}$ & 0,0000 & 1,8751 & 3,0414 \\
\hline & $10 \mathrm{AM}$ & 2,5563 & 1,3817 & 2,4771 \\
\hline
\end{tabular}

LEGENDA: AG (Água do Mar); AS (Areia Seca); AM (Areia Molhada). ÁGUA IMPRÓPRIA para o banho de acordo com Resolução CONAMA no 274 (BRASIL, 2000): Coliformes Termotolerantes : >1,0 x 103 NMP/100 $\mathrm{mL}(>3,0 \log \mathrm{NMP} / 100 \mathrm{~mL})$; Enterococcus spp.: $>1,0 \times 10^{2} \mathrm{NMP} / 100 \mathrm{~mL}(>2,0 \log \mathrm{NMP} / 100 \mathrm{~mL})$; Fungos: Não Há Padrão CLASSIFICAÇÃO DAS ÁGUAS quanto a balneabilidade de acordo com Resolução CONAMA no 274 (BRASIL, 2000): Excelente Muito Boa Satisfatória Imprópria AREIA IMPRÓPRIA (números em vermelho):

Coliformes Termotolerantes ${ }^{\mathrm{a}}:>1,0 \times 10^{5} \mathrm{NMP} / 100 \mathrm{~g}(>5,0 \log \mathrm{NMP} / 100 \mathrm{~mL})$; Enterococcus spp. $.^{\mathrm{b}}:>2,0 \times 10^{3}$ NMP/100 g (>3,3 log NMP/100 mL); Fungosa: $>1,0 \times 10^{5}$ UFC/100 g (>5,0 log UFC/100 mL)

a Mendes, Nascimento e Oliveira (1993); Vaz et al. (2005); Valdez e Grosbelli (2012).

${ }^{\mathrm{b}}$ Associação Bandeira Azul da Europa (ABAE, 2002).

Fonte: Autores (2018) 


\section{REA - Revista de estudos ambientais (Online) \\ v.20, n. 1, p.44-57, jan./jun. 2018}

Tabela 2 - Resultados das amostras de água do mar, areia seca e areia molhada em relação às análises de coliformes termotolerantes, Enterococcus spp. e fungos das respectivas praias dos municípios da Costa das Baleias. Coletas realizadas em agosto de 2015

\begin{tabular}{|c|c|c|c|c|}
\hline $\begin{array}{l}\text { PRAIAS } \\
\text { (CIDADES) }\end{array}$ & AMOSTRAS & $\begin{array}{c}\text { COLIFORMES } \\
\text { TERMOTOLERANTES } \\
\log \text { NMP } / 100 \mathrm{~mL}(\mathrm{~g})\end{array}$ & $\begin{array}{l}\text { Enterococcus spp. } \\
\text { log NMP/100 mL(g) }\end{array}$ & $\begin{array}{c}\text { FUNGOS } \\
\log \text { UFC/100 } \mathrm{mL}(\mathrm{g})\end{array}$ \\
\hline \multirow{3}{*}{$\begin{array}{c}\text { Grauçá } \\
\text { (Caravelas-BA) }\end{array}$} & $11 \mathrm{AG}$ & 0,0000 & 0,0000 & 2,6021 \\
\hline & $11 \mathrm{AS}$ & 2,5563 & 3,1761 & 5,8751 \\
\hline & $11 \mathrm{AM}$ & 0,0000 & 5,0414 & 5,1461 \\
\hline \multirow{3}{*}{$\begin{array}{c}\text { Barra } \\
\text { (Caravelas-BA) }\end{array}$} & $12 A G$ & 0,0000 & 0,0000 & 2,0000 \\
\hline & $12 \mathrm{AS}$ & 0,0000 & 3,3617 & 0,0000 \\
\hline & $12 \mathrm{AM}$ & 0,0000 & 4,3802 & 6,2304 \\
\hline \multirow{3}{*}{$\begin{array}{c}\text { Centro } \\
\text { (Prado-BA) }\end{array}$} & $13 A G$ & 2,5563 & 0,0000 & 2,4771 \\
\hline & $13 \mathrm{AS}$ & 0,0000 & 0,0000 & 4,4771 \\
\hline & $13 \mathrm{AM}$ & 4,0000 & 2,8692 & 2,0000 \\
\hline \multirow{3}{*}{$\begin{array}{l}\text { Coqueiral } \\
\text { (Prado-BA) }\end{array}$} & $14 \mathrm{AG}$ & 0,0000 & 0,0000 & 4,5911 \\
\hline & $14 \mathrm{AS}$ & 0,0000 & 0,0000 & 4,9542 \\
\hline & $14 \mathrm{AM}$ & 0,0000 & 4,6626 & 4,9542 \\
\hline \multirow{3}{*}{$\begin{array}{c}\text { Corais } \\
\text { (Alcobaça-BA) }\end{array}$} & $15 \mathrm{AG}$ & 0,0000 & 0,0000 & 4,1461 \\
\hline & $15 \mathrm{AS}$ & 0,0000 & 3,9685 & 5,3617 \\
\hline & $15 \mathrm{AM}$ & 0,0000 & 3,3617 & 4,7782 \\
\hline \multirow{3}{*}{$\begin{array}{c}\text { Centro } \\
\text { (Alcobaça-BA) }\end{array}$} & $16 \mathrm{AG}$ & 0,0000 & 0,0000 & 2,0000 \\
\hline & $16 \mathrm{AS}$ & 0,0000 & 4,1761 & 5,5911 \\
\hline & $16 \mathrm{AM}$ & 0,0000 & 4,3222 & 4,6720 \\
\hline \multirow{3}{*}{$\begin{array}{c}\text { Centro } \\
\text { (Mucuri-BA) }\end{array}$} & $17 \mathrm{AG}$ & 0,0000 & 0,0000 & 6,5051 \\
\hline & $17 \mathrm{AS}$ & 2,9638 & 0,0000 & 5,4771 \\
\hline & $17 \mathrm{AM}$ & 2,4771 & 0,0000 & 5,3010 \\
\hline \multirow{3}{*}{$\begin{array}{l}\text { Baia do Sol } \\
\text { (Mucuri-BA) }\end{array}$} & $18 \mathrm{AG}$ & 0,0000 & 0,0000 & 4,7324 \\
\hline & $18 \mathrm{AS}$ & 0,0000 & 0,0000 & 6,9912 \\
\hline & $18 \mathrm{AM}$ & 3,9542 & 0,0000 & 4,0000 \\
\hline \multirow{3}{*}{$\begin{array}{l}\text { Lugar Comum } \\
\text { (Nova Viçosa-BA) }\end{array}$} & $19 \mathrm{AG}$ & 2,4771 & 0,0000 & 4,5682 \\
\hline & 19 AS & 2,7782 & 0,0000 & 5,3424 \\
\hline & $19 \mathrm{AM}$ & 2,9638 & 0,0000 & 6,0414 \\
\hline \multirow{3}{*}{$\begin{array}{c}\text { Pau Fincado } \\
\text { (Nova Viçosa-BA) }\end{array}$} & $20 \mathrm{AG}$ & 2,8692 & 0,0000 & 4,5536 \\
\hline & $20 \mathrm{AS}$ & 2,5563 & 0,0000 & 5,1139 \\
\hline & $20 \mathrm{AM}$ & 0,0000 & 0,0000 & 4,8451 \\
\hline
\end{tabular}

LEGENDA: AG (Água do Mar); AS (Areia Seca); AM (Areia Molhada). ÁGUA IMPRÓPRIA para o banho de acordo com Resolução CONAMA no 274 (BRASIL, 2000): Coliformes Termotolerantes : >1,0 x 10³ NMP/100 $\mathrm{mL}(>3,0 \log \mathrm{NMP} / 100 \mathrm{~mL})$; Enterococcus spp.: $>1,0 \times 10^{2} \mathrm{NMP} / 100 \mathrm{~mL}(>2,0 \log \mathrm{NMP} / 100 \mathrm{~mL})$; Fungos: Não Há Padrão CLASSIFICAÇÃO DAS ÁGUAS quanto a balneabilidade de acordo com Resolução CONAMA no 274 (BRASIL, 2000): Excelente Muito Boa Satisfatória Imprópria AREIA IMPRÓPRIA (números em vermelho):

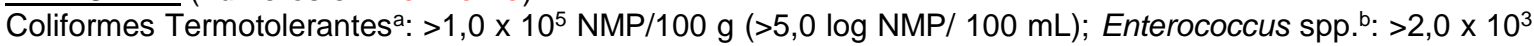
$\mathrm{NMP} / 100 \mathrm{~g}$ (>3,3 log NMP/100 mL); Fungosa: $>1,0 \times 10^{5} \mathrm{UFC} / 100 \mathrm{~g}(>5,0 \log \mathrm{UFC} / 100 \mathrm{~mL})$

a Mendes, Nascimento e Oliveira (1993); Vaz et al. (2005); Valdez e Grosbelli (2012).

${ }^{\mathrm{b}}$ Associação Bandeira Azul da Europa (ABAE, 2002). Fonte: Autores (2018) 


\section{REA - Revista de estudos ambientais (Online)}

v.20, n. 1, p.44-57, jan./jun. 2018

Tabela 3 - Resultados das amostras de água do mar, areia seca e areia molhada em relação às análises de coliformes termotolerantes, Enterococcus spp. e fungos das respectivas praias dos municípios da Costa das Baleias. Coletas realizadas em novembro de 2015

\begin{tabular}{|c|c|c|c|c|}
\hline $\begin{array}{l}\text { PRAIAS } \\
\text { (CIDADES) }\end{array}$ & AMOSTRAS & $\begin{array}{c}\text { COLIFORMES } \\
\text { TERMOTOLERANTES } \\
\text { log NMP } / 100 \mathrm{~mL}(\mathrm{~g})\end{array}$ & $\begin{array}{l}\text { Enterococcus spp. } \\
\text { log NMP/100 mL(g) }\end{array}$ & $\begin{array}{c}\text { FUNGOS } \\
\log \mathrm{UFC} / 100 \mathrm{~mL}(\mathrm{~g})\end{array}$ \\
\hline \multirow{3}{*}{$\begin{array}{c}\text { Grauçá } \\
\text { (Caravelas-BA) }\end{array}$} & $21 \mathrm{AG}$ & 0,0000 & 0,0000 & 0,0000 \\
\hline & $21 \mathrm{AS}$ & 2,5563 & 3,6317 & 4,0000 \\
\hline & $21 \mathrm{AM}$ & 0,0000 & 3,6317 & 5,5563 \\
\hline \multirow{3}{*}{$\begin{array}{c}\text { Barra } \\
\text { (Caravelas-BA) }\end{array}$} & $22 \mathrm{AG}$ & 0,0000 & 0,7782 & 3,4771 \\
\hline & $22 \mathrm{AS}$ & 0,0000 & 4,3802 & 6,1139 \\
\hline & $22 \mathrm{AM}$ & 0,0000 & 3,4314 & 4,6990 \\
\hline \multirow{3}{*}{$\begin{array}{c}\text { Centro } \\
\text { (Prado-BA) }\end{array}$} & $23 \mathrm{AG}$ & 0,0000 & 5,0414 & 2,3010 \\
\hline & $23 \mathrm{AS}$ & 0,0000 & 3,9777 & 5,0000 \\
\hline & $23 \mathrm{AM}$ & 4,0000 & 5,0414 & 2,8451 \\
\hline \multirow{3}{*}{$\begin{array}{l}\text { Coqueiral } \\
\text { (Prado-BA) }\end{array}$} & $24 A G$ & 0,0000 & 5,0414 & 3,3617 \\
\hline & $24 \mathrm{AS}$ & 0,0000 & 4,1761 & 5,0000 \\
\hline & $24 \mathrm{AM}$ & 0,0000 & 3,5798 & 5,4771 \\
\hline \multirow{3}{*}{$\begin{array}{c}\text { Corais } \\
\text { (Alcobaça-BA) }\end{array}$} & $25 \mathrm{AG}$ & 0,0000 & 5,0414 & 4,2041 \\
\hline & $25 \mathrm{AS}$ & 0,0000 & 2,9638 & 5,9542 \\
\hline & $25 \mathrm{AM}$ & 0,0000 & 2,9638 & 4,6021 \\
\hline \multirow{3}{*}{$\begin{array}{c}\text { Centro } \\
\text { (Alcobaça-BA) }\end{array}$} & $26 \mathrm{AG}$ & 0,0000 & 4,6628 & 6,0414 \\
\hline & 26 AS & 0,0000 & 4,6628 & 5,2788 \\
\hline & $26 \mathrm{AM}$ & 0,0000 & 4,4624 & 6,4914 \\
\hline \multirow{3}{*}{$\begin{array}{c}\text { Centro } \\
\text { (Mucuri-BA) }\end{array}$} & $27 \mathrm{AG}$ & 0,0000 & 0,0000 & 4,1761 \\
\hline & $27 \mathrm{AS}$ & 0,0000 & 2,6317 & 0,0000 \\
\hline & $27 \mathrm{AM}$ & 2.7782 & 3,9685 & 5,3979 \\
\hline \multirow{3}{*}{$\begin{array}{l}\text { Baia do Sol } \\
\text { (Mucuri-BA) }\end{array}$} & $28 \mathrm{AG}$ & 0,0000 & 0,0000 & 3,1761 \\
\hline & $28 \mathrm{AS}$ & 0,0000 & 2,4771 & 7,3424 \\
\hline & $28 \mathrm{AM}$ & 0,0000 & 0,0000 & 0,0000 \\
\hline \multirow{3}{*}{$\begin{array}{c}\text { Lugar Comum } \\
\text { (Nova Viçosa-BA) }\end{array}$} & $29 A G$ & 0,0000 & 0,0000 & 2,4771 \\
\hline & 29 AS & 2,8573 & 2,1761 & 5,7559 \\
\hline & $29 \mathrm{AM}$ & 0,0000 & 3,2041 & 6,0792 \\
\hline \multirow{3}{*}{$\begin{array}{c}\text { Pau Fincado } \\
\text { (Nova Viçosa-BA) }\end{array}$} & $30 \mathrm{AG}$ & 0,0000 & 0,0000 & 4,3617 \\
\hline & $30 \mathrm{AS}$ & 0,0000 & 2,9638 & 5,6021 \\
\hline & $30 \mathrm{AM}$ & 0,0000 & 2,9638 & 5,5682 \\
\hline
\end{tabular}

LEGENDA: AG (Água do Mar); AS (Areia Seca); AM (Areia Molhada). ÁGUA IMPRÓPRIA para o banho de acordo com Resolução CONAMA no 274 (BRASIL, 2000): Coliformes Termotolerantes : >1,0 x 10³ NMP/100 $\mathrm{mL}(>3,0 \log \mathrm{NMP} / 100 \mathrm{~mL})$; Enterococcus spp.: $>1,0 \times 10^{2} \mathrm{NMP} / 100 \mathrm{~mL}(>2,0 \log \mathrm{NMP} / 100 \mathrm{~mL})$; Fungos: Não Há Padrão CLASSIFICAÇÃO DAS ÁGUAS quanto a balneabilidade de acordo com Resolução CONAMA no 274 (BRASIL, 2000): Excelente Muito Boa Satisfatória Imprópria AREIA IMPRÓPRIA (números em vermelho):

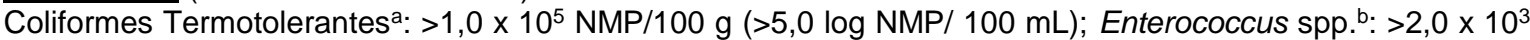
NMP/100 g (>3,3 log NMP/100 mL); Fungosa: $>1,0 \times 10^{5}$ UFC/100 g (>5,0 log UFC/100 mL)

a Mendes, Nascimento e Oliveira (1993); Vaz et al. (2005); Valdez e Grosbelli (2012).

${ }^{\mathrm{b}}$ Associação Bandeira Azul da Europa (ABAE, 2002). Fonte: Autores (2018) 


\section{REA - Revista de estudos ambientais (Online) \\ v.20, n. 1, p.44-57, jan./jun. 2018}

Tabela 4 - Resultados das amostras de água do mar, areia seca e areia molhada em relação às análises de coliformes termotolerantes, Enterococcus spp. e fungos das respectivas praias dos municípios da Costa das Baleias. Coletas realizadas em abril de 2016

\begin{tabular}{|c|c|c|c|c|}
\hline $\begin{array}{l}\text { PRAIAS } \\
\text { (CIDADES) }\end{array}$ & AMOSTRAS & $\begin{array}{c}\text { COLIFORMES } \\
\text { TERMOTOLERANTES } \\
\text { log NMP } / 100 \mathrm{~mL}(\mathrm{~g})\end{array}$ & $\begin{array}{l}\text { Enterococcus spp. } \\
\text { log NMP/100 mL(g) }\end{array}$ & $\begin{array}{c}\text { FUNGOS } \\
\log U F C / 100 \mathrm{~mL}(\mathrm{~g})\end{array}$ \\
\hline \multirow{3}{*}{$\begin{array}{c}\text { Grauçá } \\
\text { (Caravelas-BA) }\end{array}$} & $31 \mathrm{AG}$ & 0,0000 & 0,0000 & 2,9031 \\
\hline & $31 \mathrm{AS}$ & 0,0000 & 3,6335 & 4,6021 \\
\hline & $31 \mathrm{AM}$ & 0,0000 & 3,8751 & 5,0000 \\
\hline \multirow{3}{*}{$\begin{array}{c}\text { Barra } \\
\text { (Caravelas-BA) }\end{array}$} & $32 \mathrm{AG}$ & 2,8692 & 0,9638 & 2,3010 \\
\hline & $32 \mathrm{AS}$ & 0,0000 & 2,9638 & 4,6990 \\
\hline & $32 \mathrm{AM}$ & 0,0000 & 3,6335 & 4,3010 \\
\hline \multirow{3}{*}{$\begin{array}{c}\text { Centro } \\
\text { (Prado-BA) }\end{array}$} & $33 \mathrm{AG}$ & 0,0000 & 0,0000 & 2,4771 \\
\hline & $33 \mathrm{AS}$ & 0,0000 & 5,0414 & 5,2041 \\
\hline & 33 AM & 0,0000 & 4,6628 & 5,0000 \\
\hline \multirow{3}{*}{$\begin{array}{l}\text { Coqueiral } \\
\text { (Prado-BA) }\end{array}$} & $34 \mathrm{AG}$ & 0,0000 & 0,0000 & 2,0000 \\
\hline & $34 \mathrm{AS}$ & 0,0000 & 4,3802 & 4,8451 \\
\hline & $34 \mathrm{AM}$ & 0,0000 & 2,5563 & 6,2304 \\
\hline \multirow{3}{*}{$\begin{array}{c}\text { Corais } \\
\text { (Alcobaça-BA) }\end{array}$} & $35 \mathrm{AG}$ & 0,0000 & 0,0000 & 2,9031 \\
\hline & $35 \mathrm{AS}$ & 2,5563 & 3,3617 & 4,3010 \\
\hline & $35 \mathrm{AM}$ & 0,0000 & 4,6628 & 5,0000 \\
\hline \multirow{3}{*}{$\begin{array}{c}\text { Centro } \\
\text { (Alcobaça-BA) }\end{array}$} & $36 \mathrm{AG}$ & 0,0000 & 0,0000 & 3,1139 \\
\hline & $36 \mathrm{AS}$ & 2,5563 & 4,6628 & 5,1139 \\
\hline & $36 \mathrm{AM}$ & 3,6128 & 4,1761 & 2,9345 \\
\hline \multirow{3}{*}{$\begin{array}{c}\text { Centro } \\
\text { (Mucuri-BA) }\end{array}$} & $37 \mathrm{AG}$ & 0,0000 & 0,0000 & 4,2553 \\
\hline & $37 \mathrm{AS}$ & 0,0000 & 0,0000 & 4,6021 \\
\hline & $37 \mathrm{AM}$ & 0,0000 & 2,5563 & 6,4472 \\
\hline \multirow{3}{*}{$\begin{array}{l}\text { Baia do Sol } \\
\text { (Mucuri-BA) }\end{array}$} & $38 \mathrm{AG}$ & 0,0000 & 0,0000 & 2,3010 \\
\hline & 38 AS & 0,0000 & 0,0000 & 6,2041 \\
\hline & $38 \mathrm{AM}$ & 0,0000 & 3,3010 & 6,2041 \\
\hline \multirow{3}{*}{$\begin{array}{l}\text { Lugar Comum } \\
\text { (Nova Viçosa-BA) }\end{array}$} & $39 \mathrm{AG}$ & 0,0000 & 0,0000 & 3,6902 \\
\hline & 39 AS & 0,0000 & 2,5563 & 4,7782 \\
\hline & $39 \mathrm{AM}$ & 0,0000 & 2,7782 & 5,4771 \\
\hline \multirow{3}{*}{$\begin{array}{c}\text { Pau Fincado } \\
\text { (Nova Viçosa-BA) }\end{array}$} & $40 \mathrm{AG}$ & 0,0000 & 0,0000 & 4,7634 \\
\hline & $40 \mathrm{AS}$ & 0,0000 & 0,0000 & 0,0000 \\
\hline & $40 \mathrm{AM}$ & 0,0000 & 2,5563 & 4,3010 \\
\hline
\end{tabular}

LEGENDA: AG (Água do Mar); AS (Areia Seca); AM (Areia Molhada). ÁGUA IMPRÓPRIA para o banho de acordo com Resolução CONAMA no 274 (BRASIL, 2000): Coliformes Termotolerantes : >1,0 x 103 NMP/100 $\mathrm{mL}(>3,0 \log \mathrm{NMP} / 100 \mathrm{~mL})$; Enterococcus spp.: $>1,0 \times 10^{2} \mathrm{NMP} / 100 \mathrm{~mL}(>2,0$ log NMP/100 mL); Fungos: Não Há Padrão CLASSIFICAÇÃO DAS ÁGUAS quanto a balneabilidade de acordo com Resolução CONAMA no 274 (BRASIL, 2000): Excelente Muito Boa Satisfatória Imprópria $\underline{\text { AREIA }}$ IMPRÓPRIA (números em vermelho):

Coliformes Termotolerantes $^{\mathrm{a}}:>1,0 \times 10^{5} \mathrm{NMP} / 100 \mathrm{~g}(>5,0 \log \mathrm{NMP} / 100 \mathrm{~mL})$; Enterococcus spp. $.^{\mathrm{b}}:>2,0 \times 10^{3}$ NMP/100 g (>3,3 log NMP/100 mL); Fungosa: $>1,0 \times 10^{5}$ UFC/100 g (>5,0 log UFC/100 mL)

a Mendes, Nascimento e Oliveira (1993); Vaz et al. (2005); Valdez e Grosbelli (2012).

${ }^{b}$ Associação Bandeira Azul da Europa (ABAE, 2002). Fonte: Autores (2018)

As condições de balneabilidade de uma praia podem sofrer influência de vários fatores, como precipitação, marés, correntes marinhas e ventos, esgotamento sanitário e sistema de drenagem, expansão urbana 


\section{REA - Revista de estudos ambientais (Online) v.20, n. 1, p.44-57, jan./jun. 2018}

desordenada, etc. (VALADÃO; ARAÚJO, 2012).

Monteiro (2013) analisou, no período de fevereiro a maio de 2012, semanalmente, o monitoramento das águas das praias do Iguape e do Presídio, ambas em Aquiraz, Ceará. Os resultados obtidos para o NMP de Escherichia coli nas amostras de águas das praias apresentaram um valor mínimo $<1,8$ $\mathrm{NMP} / 100 \mathrm{NMP} / \mathrm{mL}$ na maioria das amostras e um máximo de $35.000 \mathrm{NMP} / 100 \mathrm{~mL}$. Os resultados obtidos para o NMP de Enterococcus spp. nas amostras de água das praias apresentaram um resultado mínimo $<1,8$ NMP/100 mL aumentando posteriormente. De acordo com os resultados microbiológicos obtidos, as duas praias estavam impróprias para banho em todo o período estudado devido ao número de Enterococcus spp. estar fora dos limites estipulados pela resolução $\mathrm{n}^{\circ} 274$ do CONAMA (BRASIL, 2000).

Souza e Silva (2015) avaliaram a qualidade ambiental das praias da llha de Itaparica-BA. As coletas foram realizadas em dois períodos: durante a alta estação (mês de janeiro de 2013) e durante a baixa estação (mês de julho de 2013). A análise de coliformes termotolerantes e totais nas areias indicaram que todas as praias, na alta estação, foram consideradas próprias, de acordo com Mendes, Nascimento e Oliveira (1993), Vaz et al. (2005), Valdez e Grosbelli (2012), para contato primário e enquadradas na categoria de excelentes. Já no período de baixa estação, apenas as areias da praia de Barra Grande foram consideradas próprias.

De acordo com a enumeração de coliformes termotolerantes em areias, durante todos os meses amostrados, apenas duas $(5,0 \%)$ amostras apresentaram a areia seca com valores acima dos padrões estabelecidos e uma (2,5\%) em areia molhada. Em relação aos níveis de contaminação por Enterococcus spp., 14 (35\%) das amostras de areia seca e 16 $(40 \%)$ em amostras de areia molhada apresentaram valores acima do recomendado, de acordo com Mendes, Nascimento e Oliveira (1993), Vaz et al. (2005), Valdez e Grosbelli (2012) (Tabelas 1 a 4).

Mendes, Nascimento e Oliveira (1993), a fim de contribuírem para pesquisas com a contaminação das areias de praias, utilizaram como indicadores as bactérias Escherichia coli. Todavia, estudos mostram que as bactérias do gênero Enterococcus parecem se acumular mais na areia (ALM;
BURKE; SPAIN, 2003). Assim sendo, as bactérias do gênero Enterococcus seriam ótimos indicadores de contaminação para esse tipo de ambiente. Tais pesquisas corroboram com os resultados encontrados, já que os níveis de contaminação (enumeração de microrganismos analisados) por Enterococcus spp. foram maiores do que os de coliformes termotolerantes. Além disso, segundo Dufour (1984), as bactérias do gênero Enterococcus são consideradas como um indicador de excelência para a classificação das águas salinas, uma vez que eles apresentam um amplo tempo de sobrevivência e maior resistência quando comparados à Escherichia coli e aos coliformes termotolerantes.

Sobre o nível de contaminação por fungos, $16(40 \%)$ das amostras de areia seca e $15(37,5 \%)$ de areia úmida apresentaram contagem acima do recomendado (Tabelas 1 a 4). Não existe legislação para os níveis toleráveis de fungos em águas, porém, caso seja considerado o mesmo que para as areias $\left(>1,0 \times 10^{5}\right.$ UFC/100 mL ou $>5,0$ log $\mathrm{NMP} / 100 \mathrm{~mL})$, apenas três $(7,5 \%)$ amostras de água estariam com contagem acima do recomendado. Segundo Silva et al. (2007) e Monteiro (2013), os fungos, que são seres filamentosos ou leveduriformes, obtêm nutrientes através de matéria orgânica em decomposição ou de hospedeiros (quando parasitas) sendo bem difundidos na natureza, vivendo no solo, no ar e na água podendo causar doenças como infecções cutâneas, das mucosas, infecções disseminadas e profundas em indivíduos debilitados ou imunodeprimidos.

Monteiro (2013) analisou, no período de fevereiro a maio de 2012, semanalmente, a qualidade de 12 (doze) amostras de areia seca e 12 molhadas, totalizando 24 amostras ao final do experimento nas praias Iguapé e Presídio. A areia seca da praia do Iguapé apresentou os seguintes resultados, $E$. coli entre 3,0 e $240 \mathrm{NMP} / \mathrm{g}$ e Enterococcus spp. entre 43 e $10.000 \mathrm{NMP} / \mathrm{g}$. O resultado mínimo obtido para leveduras na areia seca da praia do Iguapé foi $<10 \mathrm{UFC} / \mathrm{g}$ e o máximo de $7.750 \mathrm{UFC} / \mathrm{g}$. A areia molhada da praia do Iguapé apresentou os resultados de 3,0 a $75 \mathrm{NMP} / \mathrm{g}$ e de 3,0 a $43 \mathrm{NMP} / \mathrm{g}$., para E. coli e Enterococcus spp., respectivamente Os resultados obtidos de leveduras na areia molhada da praia do Iguapé e do Presídio apresentaram contagem $<10$ UFC/g. Para o autor, a exploração de pontos turísticos traz benefícios à região, mas por outro lado pode conduzir a um risco à saúde pública dos 


\section{REA - Revista de estudos ambientais (Online)}

v.20, n. 1, p.44-57, jan./jun. 2018

frequentadores. Os resultados microbiológicos das areias secas e molhadas apresentaram uma maior contaminação na praia do Iguapé.

Vieira et al. (2001) pesquisando $E$. coli, Vibrio parahaemolyticus, Salmonella spp. e a levedura Candida albicans em 30 amostras de areia da praia do Futuro, no litoral de Fortaleza, entre maio de 1999 e janeiro de 2000, encontraram maior contaminação de $E$. coli na areia seca. A presença de $E$. coli nas areias indica contaminação fecal recente. Estas bactérias são carreadas através de córregos, canais de drenagens, águas pluviais que recebem esgoto doméstico, lixo e outros detritos.

As praias do Centro e do Coqueiral, em Prado, e as praias do Centro e dos Corais em Alcobaça encontravam-se com as piores médias de contagem de Enterococcus spp.na água do mar (acima do padrão), indicando estarem impróprias em relação à balneabilidade (Tabela 5).

Tabela 5 - Médias dos valores encontrados da enumeração de coliformes termotolerantes;

Enterococcus spp. e fungos das amostras de água do mar das praias dos municípios que fazem parte da Costa das Baleias

\begin{tabular}{ccccc}
\hline CIDADES & PRAIAS & $\begin{array}{c}\text { Coliformes } \\
\text { Termotolerantes } \\
(\log \text { NMP/100 } \mathbf{~ m L})\end{array}$ & $\begin{array}{c}\text { Enterococcus spp. } \\
\text { (log NMP/100 } \mathbf{~ m L})\end{array}$ & $\begin{array}{c}\text { Fungos } \\
\text { (log UFC/100 } \mathbf{~ m L})\end{array}$ \\
\hline \multirow{2}{*}{ Caravelas } & Grauçá & 0,0000 & 0,8950 & 2,0511 \\
& Barra & 1,3564 & 1,2759 & 2,7983 \\
\hline \multirow{2}{*}{ Prado } & Centro & 1,2782 & $\mathbf{2 , 1 0 0 8}$ & 2,3138 \\
& Coqueiral & 0,7410 & $\mathbf{2 , 0 5 4 4}$ & 3,1995 \\
\hline \multirow{2}{*}{ Alcobaça } & Centro & 0,0000 & $\mathbf{2 , 0 7 4 1}$ & 2,7888 \\
& Corais & 0,0000 & $\mathbf{2 , 1 6 8 7}$ & 3,5246 \\
\hline \multirow{2}{*}{ Mucuri } & Centro & 0,0000 & 0,6391 & 5,0697 \\
& Baia do Sol & 0,0000 & 0,7410 & 3,0524 \\
\hline \multirow{2}{*}{ Nova Viçosa } & Lugar Comum & 0,6193 & 0,7591 & 2,6839 \\
& Pau Fincado & 0,7173 & $\mathbf{0 , 8 9 5 0}$ & 4,2394 \\
\hline \multicolumn{2}{c}{ PADRÃO TOLERÁVEL* } & Até 3,0000 & Até 2,0000 & Não Há Padrão \\
\hline
\end{tabular}

* Resolução CONAMA no 274 (BRASIL, 2000)

Fonte: Autores (2018)

A praia do Grauçá em Caravelas e a praia do Centro em Alcobaça encontravamse com as piores médias na contagem de enterococos na areia seca e as praias dos
Corais e Baia do Sol em Alcobaça e Mucuri, respectivamente, apresentaram valores acima do padrão na contagem de fungos na areia seca (Tabela 6).

Tabela 6 - Médias dos valores encontrados da enumeração de coliformes termotolerantes; Enterococcus spp. e fungos das amostras de areia seca das praias dos municípios que fazem parte da Costa das Baleias

\begin{tabular}{ccccc}
\hline CIDADES & PRAIAS & $\begin{array}{c}\text { Coliformes } \\
\text { Termotolerantes } \\
(\log \text { NMP/100 } \mathbf{~ m L})\end{array}$ & $\begin{array}{c}\text { Enterococcus spp. } \\
(\log \text { NMP/100 } \mathbf{~ m L})\end{array}$ & $\begin{array}{c}\text { Fungos } \\
\text { (log UFC/100 } \mathbf{~ m L})\end{array}$ \\
\hline \multirow{2}{*}{ Caravelas } & Grauçá & 2,0191 & 3,3707 & 4,5544 \\
& Barra & 0,9921 & 3,0848 & 3,5229 \\
\hline \multirow{2}{*}{ Prado } & Centro & 1,2604 & 2,8498 & 4,7213 \\
& Coqueiral & 1,2604 & 2,6079 & 4,7854 \\
\hline \multirow{2}{*}{ Alcobaça } & Centro & 1,2782 & 4,1358 & 4,9458 \\
& Corais & 1,2584 & 2,9819 & 5,0492 \\
\hline \multirow{2}{*}{ Mucuri } & Centro & 1,3800 & 1,3236 & 3,5774 \\
& Baia do Sol & 0,0000 & 0,9597 & 5,1344 \\
\hline \multirow{2}{*}{ Nova Viçosa } & Lugar Comum & 2,3400 & 2,2782 & 4,7191 \\
& Pau Fincado & 0,6391 & 1,2047 & 3,4394 \\
\hline \multicolumn{2}{c}{ PADRÃO TOLERÁVEL } & Até 5,0000 & Até 3,3010 & Até 5,000 \\
\hline
\end{tabular}

a Mendes, Nascimento e Oliveira. (1993); Vaz et al. (2005); Valdez e Grosbelli (2012).

${ }^{\mathrm{b}}$ Associação Bandeira Azul da Europa (ABAE, 2002).

Fonte: Autores (2018) 
A praia do Centro, em Prado e a praia do Centro, em Alcobaça encontravamse com as piores médias de contagem de enterococos na areia molhada, e as praias
Coqueiral no Prado e Lugar Comum em Nova Viçosa apresentaram valores acima do padrão na contagem de Fungos na areia molhada (Tabela 7).

Tabela 7 - Médias dos valores encontrados da enumeração de coliformes termotolerantes; Enterococcus spp. e fungos das amostras de areia molhada das praias dos municípios que fazem parte da Costa das Baleias.

\begin{tabular}{ccccc}
\hline CIDADES & PRAIAS & $\begin{array}{c}\text { Coliformes } \\
\text { Termotolerantes } \\
\text { (log NMP/100 } \mathbf{~ L L})\end{array}$ & $\begin{array}{c}\text { Enterococcus spp. } \\
\text { (log NMP/100 mL) }\end{array}$ & $\begin{array}{c}\text { Fungos } \\
\text { (log UFC/100 } \mathbf{~ m L})\end{array}$ \\
\hline \multirow{2}{*}{ Caravelas } & Grauçá & 0,8306 & 3,1371 & 4,8459 \\
& Barra & 1,0198 & 2,9806 & 4,9027 \\
\hline \multirow{2}{*}{ Prado } & Centro & 3,5806 & 3,5383 & 3,4811 \\
& Coqueiral & 0,6391 & 3,0249 & 5,1170 \\
\hline \multirow{2}{*}{ Alcobaça } & Centro & 1,5423 & 3,8207 & 4,3973 \\
& Corais & 0,8404 & 3,1054 & 4,7400 \\
\hline \multirow{2}{*}{ Mucuri } & Centro & 1,9529 & 2,1000 & 4,9811 \\
& Baia do Sol & 1,4886 & 1,3174 & 3,3586 \\
\hline \multirow{2}{*}{ Nova Viçosa } & Lugar Comum & 1,5350 & 1,9877 & 5,3972 \\
& Pau Fincado & 0,6391 & 1,7255 & 4,2979 \\
\hline \multicolumn{2}{c}{ PADRÃO TOLERÁVEL } & Até 5,0000 & Até 3,3010 & Até 5,000 \\
\hline
\end{tabular}

a Mendes, Nascimento e Oliveira (1993); Vaz et al. (2005); Valdez e Grosbelli (2012).

${ }^{\mathrm{b}}$ Associação Bandeira Azul da Europa (ABAE, 2002). Fonte: Autores (2018)

Verificou-se que houve diferença significativa $(p<0,001)$ entre os valores encontrados de contaminação pelos respectivos microrganismos (coliformes termotolerantes, Enterococcus spp. e fungos) pesquisados entre o nível de contaminação da água e o das areias analisadas. Não houve diferença significativa entre as areias seca e molhada (Tabela 8 e Figura 2).

Tabela 8 - Resultado das Médias e Desvio Padrão da contagem de microrganismos em diferentes locais de coleta de amostras

\begin{tabular}{cccc}
\hline $\begin{array}{c}\text { LOCAIS } \\
\text { DE }\end{array}$ & \multicolumn{3}{c}{$\begin{array}{c}\text { MICRORGANISMOS } \\
\text { (log NMP/100 mL ou g) }\end{array}$} \\
\cline { 2 - 4 } COLETA & $\begin{array}{c}\text { Coliformes } \\
\text { Termotolerantes }\end{array}$ & Enterococcus spp. & Fungos \\
\hline Água do Mar & $0,4712^{\mathrm{a}} \pm 1,04$ & $1,3603^{\mathrm{b}} \pm 1,86$ & $3,1721^{\mathrm{d}} \pm 1,46$ \\
Areia Seca & $1,2427^{\mathrm{b}} \pm 1,63$ & $2,4802^{\mathrm{c}} \pm 1,62$ & $4,4449^{\mathrm{e}} \pm 1,76$ \\
Areia Molhada & $1,4068^{\mathrm{b}} \pm 1,78$ & $2,6737^{\mathrm{c}} \pm 1,57$ & $4,3519^{\mathrm{e}} \pm 1,54$ \\
\hline
\end{tabular}

a, b, c, d, e letras iguais, médias semelhantes pelo teste de Tukey ao nível de $5 \%$ de probabilidade.

Fonte: Autores (2018)

Os sedimentos devem receber atenção especial, uma vez que atuam como filtros que concentram vários tipos de poluentes, deixando-os armazenados. Alguns trabalhos já vêm demonstrando que as concentrações bacterianas encontradas nas areias têm sido superiores às encontradas na coluna de água (ANDRADE et al., 2015). Esse fato pode ocorrer, uma vez que as bactérias podem sobreviver por mais tempo nesse ambiente (WHITMAN; NEVERS, 2003), por encontrarem condições favoráveis de nutrientes (BRUNKE;
FISCHER, 1999), proteção contra os raios solares (DAVIES-COLLEY et al., 1999) e contra a predação por protozoários (DAVIES; BAVOR, 2000).

Durante as coletas realizadas nas praias de Nova Viçosa (Praia Lugar Comum e Pau Fincado), Mucuri (Praia Baia do Sol), Caravelas (Praia da Barra) e Alcobaça (Praia do Centro), observou-se grande quantidade de resíduo sólido nestes ambientes, tais como fezes de animais, carcaças de animais $\mathrm{e}$ iscas de peixes. 


\section{REA - Revista de estudos ambientais (Online) v.20, n. 1, p.44-57, jan./jun. 2018}

$\mathrm{Na}$ Praia da Barra (Caravelas) observou-se, durante todas as coletas, grande quantidade de resíduo sólido, na areia da praia. Tal fato pode ser explicado, pois esta praia é um dos principais locais de ancoragem dos barcos de pesca da cidade, o que evidencia um grande fluxo de pessoas que por vezes não fazem o descarte do resíduo sólido de forma adequada. $\mathrm{O}$ resíduo sólido encontrado consistia em embalagens de óleo utilizadas pelos pescadores e lixo domiciliar que provavelmente era originado pelos moradores e turistas de Caravelas.

Figura 2 - Contagem de microrganismos em relação aos diferentes locais de coleta de amostras

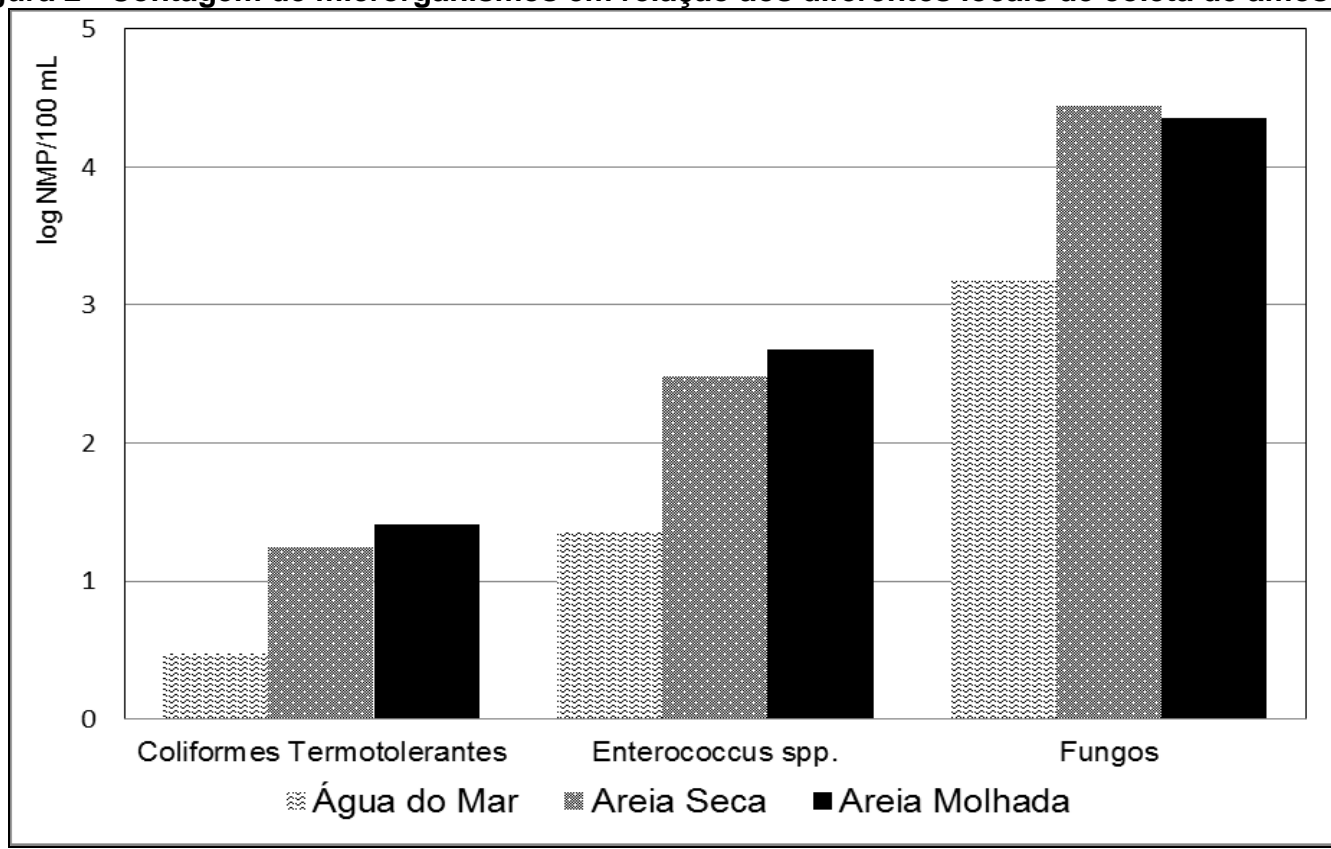

Fonte: Autores (2018)

Nas praias do Centro e Baía do Sol (Mucuri) e na praia do Centro (Alcobaça) foram observadas uma grande quantidade de fezes de cães na areia uma vez que era comum encontrar estes animais transitando na areia da praia, nas vias de passeio para pedestres e na área peridomiciliar, demonstrando assim que os cães desempenham um importante papel como fonte de contaminação ambiental de microrganismos patogênicos e parasitos com potencial zoonótico.

Segundo Schantz et al. (1991), os cães desempenham o papel de hospedeiro definitivo para algumas espécies de helmintos, que podem causar enfermidades importantes para o homem. Além disso, o crescente número de cães domiciliados, peridomiciliados e errantes, de modo geral, em todo o Brasil, associado ao fácil acesso destes animais a locais de lazer, aumenta o risco de infecção, especialmente para crianças (NUNES et al., 2000).

$\mathrm{Na}$ coleta realizada em novembro de 2015 na Praia do Pau Fincado (Nova Viçosa), foi observado o despejo de iscas mortas, feito por pescadores locais, após uma pesca. Estas iscas foram despejadas diretamente na areia da praia e apresentavam um odor característico que atraiu a presença de urubus-de-cabeça-preta (Coragyps atratus).

O urubu-de-cabeça-preta é uma ave de vida livre e de grande distribuição no Brasil (BARBARA, 2015). Esses animais apresentam hábitos necrófagos e utilizam quase que exclusivamente de carcaças de animais mortos para compor sua dieta (FERGUSON-LEES; CHRISTIE, 2001). Não obstante a sua função em ambientes naturais, o papel dos urubus-de-cabeçapreta na epidemiologia de diversas doenças infecciosas ainda não foi elucidado (LOWNEY, 1999).

Embora os urubus-de-cabeça-preta de vida livre estejam adaptados aos ambientes urbanos e possam servir como potenciais veiculadores de doenças, até 0 presente momento, estudos que avaliem o perfil sanitário dessas aves são escassos (BARBARA, 2015). 


\title{
REA - Revista de estudos ambientais (Online) v.20, n. 1, p.44-57, jan./jun. 2018
}

\section{Conclusões}

As águas e areias das praias analisadas apresentaram níveis de contaminação relevantes em relação à higiene-sanitária das praias. Tanto a areia seca quanto a úmida teve maior contaminação por coliformes termotolerantes, Enterococcus spp. e fungos do que a água do mar indicando um alto risco de contaminação àqueles que frequentam estas praias. Os altos índices de contaminação encontrados principalmente em relação aos Enterococcus spp. nas águas e areias das praias dos municípios da Costa das Baleias demonstram a necessidade de esclarecer e orientar a população sobre os riscos de veiculação de doenças infecciosas, além da importância de informar sobre medidas de prevenção que devem ser adotadas para diminuir o nível de contaminação destas praias e ampliar a fiscalização e o saneamento público nestas áreas, tornando de suma importância medidas mitigatórias para a proteção da saúde da população que frequentam estes locais.

\section{Microbiological Evaluation of Sand and Water of Beaches in the Coastal Towns on the Baleias Coast, Brazil}

\begin{abstract}
Water is one of the main media of transmission of infectious and parasitic diseases, though beach sands also stand as an important source of diseases to people going to beaches. Due to the constant use of such environments, mainly in tourist towns, biological monitoring is necessary as a means to reduce health hazards. This study evaluated the quality of sand and water samples in coastal towns in Baleias Coast, southern Bahia, Brazil. Microbiological analyses included counts of thermotolerant coliforms, Escherichia coli, Enterococcus spp., filamentous fungi, and yeasts. Sands and waters in the beaches surveyed presented high contamination levels, affecting the hygiene and sanitation conditions of these environments. There was a higher contamination of the sands in relation to water and a greater detection of Enterococcus spp. in relation to thermotolerant coliforms.
\end{abstract}

Keywords: Water; Beach; Coliform; Enterococci; Bathing.

\section{Referências}

ABAE (Associação Bandeira Azul da Europa). Qualidade Microbiológica de Areias de Praias Litorais. Alfragide: Instituto do Ambiente (IA). 2002.

ALM, E. W.; BURKE, J.; SPAIN, A. Fecal indicator bacteria are abundant in wet sand at freshwater beaches. Water Research. v. 37, p. 3.978-3.982, 2003.

ANDRADE, V. C. ZAMPIERI, B. D. B. BALLESTEROS, E. R. PINTO, A. B. OLIVEIRA, A. J. F. C. Densities and antimicrobial resistance of Escherichia coli isolated from marine waters and beach sands. Environmental Monitoring and Assessment. v. 187, p. 342-357, 2015.

APHA (American Public Health Association). Standard Methods for the Examination of Water and Wastewater. 21. ed. Washington: APHA. 2005. $1.336 \mathrm{p}$.

ARAÚJO, F. V.; SILVA, M. L.; CASTRO, R. O. SALES, A. S.; TIMBÓ, M. F.; PEREZ, F. B; Relato: Projeto "Praia limpa é a minha praia": uma contribuição para a preservação dos ambientes aquáticos. Interagir: Pensando a Extensão. $n$. 17/18/19, p. 81- 89, 2014.
AYRES, M. AYRES JR., M. AYRES, D. L; SANTOS, A. A. S. BioEstat 5.3 - Aplicações Estatísticas nas Áreas das Ciências Biomédicas. Belém: Instituto Mamirauá. 2007. $364 \mathrm{p}$.

BARBARA, J. C. A. Avaliação do perfil sanitário de urubu-de-cabeça-preta (Coragyps atratus) em ambiente urbano. São Paulo, 2015. 66 p. Dissertação (Programa de Pós-Graduação em Patologia Experimental e Zootecnia) - Faculdade de Medicina Veterinária e Zootecnia. Universidade de São Paulo, São Paulo, 2015.

BARROS, D. J. MARQUES, A. K.; MORAIS, P. B. Avaliação ambiental com base em indicador biológico de balneabilidade no município de Palmas-TO. Journal of Bioenergy and Food Science. v. 2, n. 4, p. 172-177, 2015.

BRASIL. Ministério do Meio Ambiente (MMA). Conselho Nacional de Meio Ambiente (CONAMA). Resolução $\mathbf{n}^{\circ}$ 274, de 29 de novembro de 2000. Dispõe sobre a qualidade das águas de balneabilidade e alerta o disposto na Resolução 020, de 18 de junho de 1986. Diário Oficial da República Federativa do Brasil, Brasília, 8 jan. 2001. 


\section{REA - Revista de estudos ambientais (Online) v.20, n. 1, p.44-57, jan./jun. 2018}

CASTRO, H. M. P. Efeito da radiação solar e da salinidade sobre o crescimento de Escherichia coli. Fortaleza. 2003. 54 p. Dissertação (Mestrado em Ciências Marinhas Tropicais) - Instituto de Ciências do Mar, Universidade Federal do Ceará, Fortaleza, 2003.

DAVIES, C. M.; BAVOR, H. J. The fate of storm water associated bacteria in constructed wetland and water pollution control pond systems. Journal of Applied Microbiology. v. 89, n. 2, p. 349-360, 2000.

DAVIES-COLLEY, R. J; DONNISON, A. M.; SPEED, D. J.; ROSS, C. M.; NAGELS, J. W. Inactivation of fecal indicator microorganisms in waste stabilization ponds: interactions of environmental factors with sunlight. Water Research. v. 33, n. 5, p. 1.220-1.230, 1999.

DUFOUR, A.P. Bacterial indicators of recreational water quality. The Canadian Journal of Public Health. v. 75, n. 1, p. 49-56, 1984.

FERGUSON-LEES, J.; CHRISTIE, D. A. Order Ciconiformes, family Cathartidae (New world vultures). In: FERGUSON-LEES, J.; CHRISTIE, D. A. Raptors of the World. Boston: Houghton Mifflin Company. 2001. 320 p.

HOLT, J. G.; KRIEG, N. R.; SNEATH, P. H. A.; STALEY, J. T.; WILLIANS, S. T. (Eds.). Bergey's Manual of Determinative Bacteriology. v. 1. 9. ed. Baltimore: Williams \& Wilkins. 1994.

LOWNEY, M. S. Damage by black and turkey vultures in Virginia, 1990-1996. Wildlife Society Bulletin. v. 27, n. 3, p.715-719, 1999.

MENDES, B.; NASCIMENTO, M. J.; OLIVEIRA, J. S. Preliminary characterization and proposal of microbiological quality standard of sand beaches. Water Science and Technology. v. 27, p. 453456, 1993.

MONTEIRO, D. T. L. Comparação da qualidade bacteriológica da água marinha e da areia seca e molhada de duas praias do litoral leste do Ceará. 2013. 71 p. Dissertação (Mestrado em Ciências Marinhas Tropicais). Universidade Federal do Ceará. Instituto de Ciências do Mar, Fortaleza, 2013.

NUNES, C. M., PENA, F. C.; NEGRELLI, G. B.; ANJO, C. G. S.; NAKANO, M. M.; STOBBE, N. S. Ocorrência de larva migrans na areia de áreas de lazer das escolas municipais de ensino infantil,
Araçatuba, SP, Brasil. Revista de Saúde Pública. v. 34, p. 656-658, 2000.

SCHANTZ P. M. Parasitic zoonosis in perspective. International Journal for Parasitology. v. 21, $p$. 161-170, 1991.

SILVA, N.; JUNQUEIRA, V. C. A.; SILVEIRA, N. F. A.; TANIWAKE, M. H.; SANTOS, R. F. S.; GOMES, R. A. R. Manual de Métodos de Análise Microbiológica de Alimentos. 3. ed. São Paulo: Varela. 2007, 536 p.

SOUZA, J. L.; SILVA, I. R. Avaliação da qualidade ambiental das praias da ilha de Itaparica, Baía de Todos os Santos, Bahia. Revista Sociedade \& Natureza. v. 27, n. 3, p. 469-484, 2015.

VALADÃO, C. E. A.; ARAÚJO, A. L. C. Avaliação da condição de balneabilidade das praias de Natal-RN no período de 2004-2009. HOLOS. v. 4. p. 1-18, 2012.

VALDEZ, R. H.; GROSBELLI, P. P. Análise microbiológica de areias de praças públicas da cidade de Palmas (PR). Ambiência. v. 8, n. 3, p. 833-844, 2012

VAZ, L. O.; SILVA, M. B.; RAMOS, A. D. GONÇALVES, R. F.; CASSINI, S. T. A. Consolidação dos dados sobre a qualidade sanitária de areias de contato primário em escolas e logradouros públicos da cidade de Vitória-ES. In: CONGRESSO BRASILEIRO DE ENGENHARIA SANITÁRIA E AMBIENTAL, 23. Campo Grande. Anais... Campo Grande: Abes. 2005. p. 1-5. 2005

VIEIRA, R. H. S. F; SILVA, P. R. F. G.; SOUSA, O. V.; LEITUGEUR, L. G. O. Balneabilidade das águas da praia do Futuro. Arquivo Ciência do Mar. v. 34, p. 39-42, 2001

WHITMAN, R. L.; NEVERS, M. B. Foreshore sand as a source of Escherichia coli in nearshore water of a Lake Michigan beach. Applied Environmental Microbiology. v. 69, n. 9, p. 5.555- 5.562, 2003.

\section{Agradecimentos}

Ao Conselho Nacional de Desenvolvimento Científico (CNPq) e ao Programa Institucional de Bolsas de Iniciação Científica (PIBIC). 